\title{
Brown Tumor: A Late Complication of Secondary Hyperparathyroidism
}

\author{
Amanda Azevedo Torres ${ }^{1}$, Andressa Araújo da Silva ${ }^{2}$, Amanda Maria Lopes da Silva ${ }^{2}$, Brunna da Silva Firmino ${ }^{2}$, \\ Jean de Pinho Mendes ${ }^{2}$, Darklilson Pereira Santos ${ }^{3}$ and Antonione Santos Bezerra Pinto ${ }^{3,4 *}$ \\ ${ }^{1}$ Undergraduate medical student at the Federal University of Piauí \\ ${ }^{2}$ Undergraduate dental student at the State University of Piauí \\ ${ }^{3}$ Dentistry professor at the State University of Piauí \\ ${ }^{4}$ Medical professor at the Faculty of Human, Exact and Health Sciences of Piaui of the Higher Education Institute of the Vale do Parnaíba
}

Received: 些 June 26, 2018; Published: 眥July 06, 2018

*Corresponding author: Antonione Santos Bezerra Pinto,Dentistry professor at the State University of Piauí, Medical professor at the Faculty of Human, Exact and Health Sciences of Piaui of the Higher Education Institute of the Vale do , Parnaíba

\begin{abstract}
Brown tumor is characterized by atypical non-neoplastic bone lesions caused by an accelerated osteoclastic activity and peritrabecular fibrosis due to hyperparathyroidism, resulting in a local damage phenomenon. It is more common in large bones, ribs and pelvis, but can occur in any bone. We describe a case of a 55-year-old woman undergoing hemodialysis for eight years, with development of a lingual mass in the floor of the mouth, which was histologically diagnosed as a brown tumor. Radiological e clinical features are also described. Brown Tumor requires an early diagnosis and multidisciplinary follow up to avoid fractures, deformities and functional alterations.
\end{abstract}

Keywords: Nephrectomy; Chronic Pyelonephritis; Hydronephrosis; Clear Cell Renal Cell Carcinoma

Abbreviations: BT: Brown Tumor; HP: Hyperparathyroidism; CKD: Chronic Kidney Disease; CT: Computed Tomography; SHPT: Secondary Hyperparathyroidism

\section{Introduction}

Brown tumor (BT) is characterized by atypical non-neoplastic bone lesions caused by an accelerated osteoclastic activity and peritrabecular fibrosis due to hyperparathyroidism (HP), resulting in a local destroying phenomenon [1,2]. The term "brown tumor" originates from the excessive hemorrhages, vascularization and hemosiderin deposition in the tissue [3]. It is more common in large bones, ribs and pelvis, but can occur in any bone. Important jaw lesions are rare, corresponding to $0.1 \%$ of cases [2,3].Brown tumors associated with primary hyperparathyroidism have a frequency of 3-4\%, whereas those associated with chronic kidney disease (CKD) has an incidence rate of 1.5\%[4].

New cases are constantly reported mainly due to the survival increase of patients [5,6], especially the cases related to hemodialysis [1].This tumor has a close association with secondary $\mathrm{HP}$, mainly regarding chronic kidney patients, as it has a negative impact on their life quality due to its high morbidity and mortality. In fact, this clinical condition is directly linked to an increase in bones fractures, hospitalization and mortality as a result of the gradual reduction of mineral bone density [7]. Furthermore, the lesion is microscopically similar to central giant-cell granuloma, aneurysmatic bone cyst and cherubism, which are benign but have an expansive growth, which could be mistakenly diagnosed and lead to wrong treatments and sequels as a result [8]. We report a BT case due to secondary HP resulting from CKD aiming to understand its clinical presentation and physiopathology.

\section{Case Report}

A 55-year-old woman was been undergoing routine hemodialysis for eight years, three times a week, due to chronic kidney disease (CKD) secondary to systemic arterial hypertension. She complained of a progressive development of a painless lingual mass in the anterior portion of the mandible, with flaccid consistency and without local phlogistic signs. There were no alterations in oral mucosa either. The mass had imprecise limits, extending toward the left and right premolar regions and causing expansion into the tongue cortical area (Figure 1).Panoramic mandible radiography showed loss of lamina dura and radiopaqueimage with welldefined contours of the buccal floor. Computed tomography (CT) scan revealed multilocular radiolucent lesions with expansion into 
the jaw, revealing bone loss (Figure 2).Ultrasonography (Figure 3) showed a hyperechoic oval mass with a lobulated contour and partially-defined limits, measuring approximately 4.3 × 3.7 × 2.4 $\mathrm{cm}$ (volume of $19.8 \mathrm{~cm}^{3}$ ) and presenting an expansive character, located in the buccal floor superiorly. When analyzing the thyroid gland, we observed a heterogeneous echotexture characterized by the presence of four bilateral solid oocyte nodules and two simple cysts in the right lobe, causing an increase in the total thyroid volume to $23.82 \mathrm{~cm}^{3}$ in comparison to $14 \mathrm{~cm}^{3}$ for normal cases. Also, a volumetric increase of the parathyroids with a calcified halo in the right was observed.

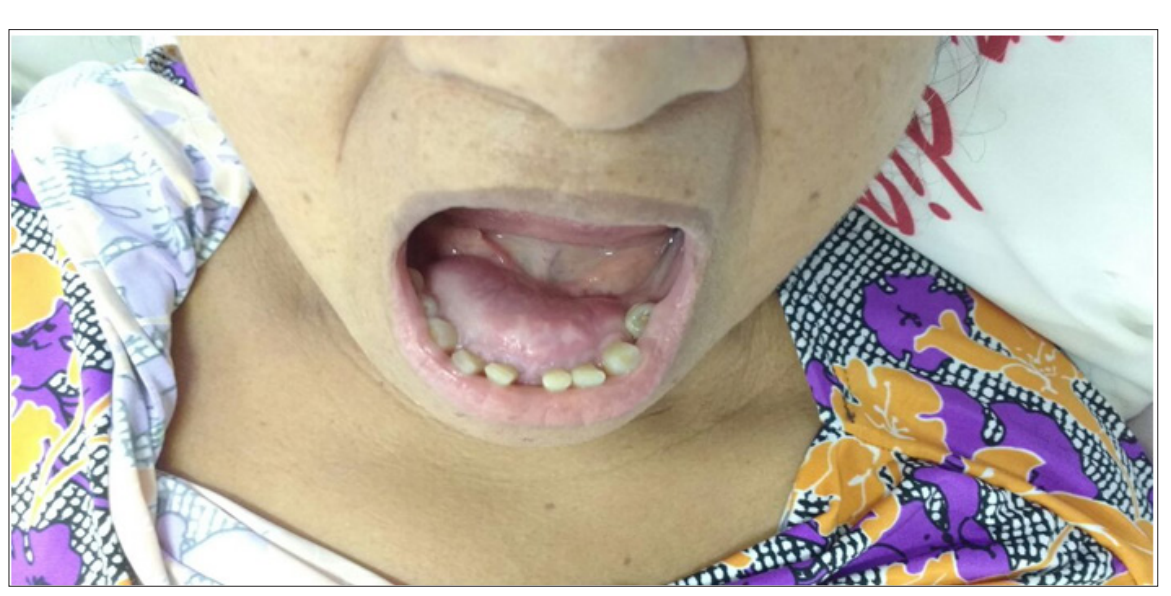

Figure 1: On physical examination, one can see a bulge on the buccal floor in the anterior mandibular region, without phlogistic signs.

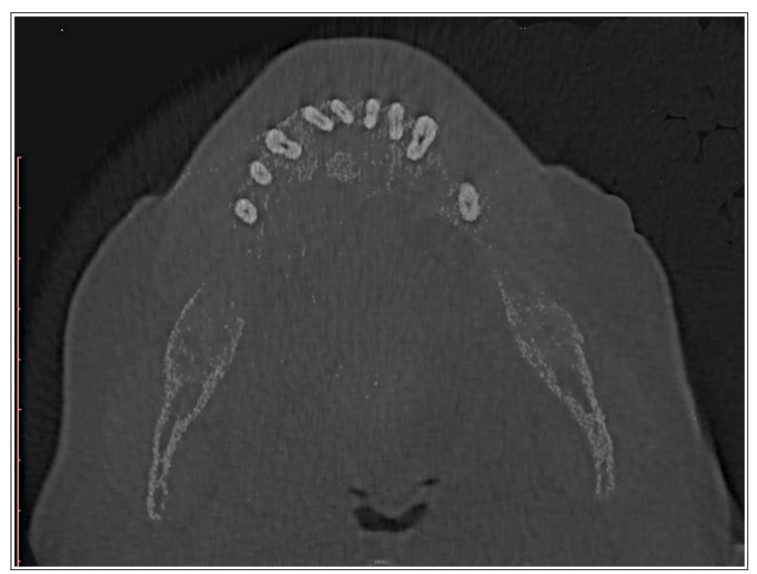

Figure 2: CT axial section of the mandible revealing hypodense lesion with areas of diffuse bone resorption, with lingual cortical expansion, thinning and perforation of it. It is also possible to observe that the bone marrow density is similar to that of soft tissues not only in the lesion area, indicating generalized osteodystrophy.

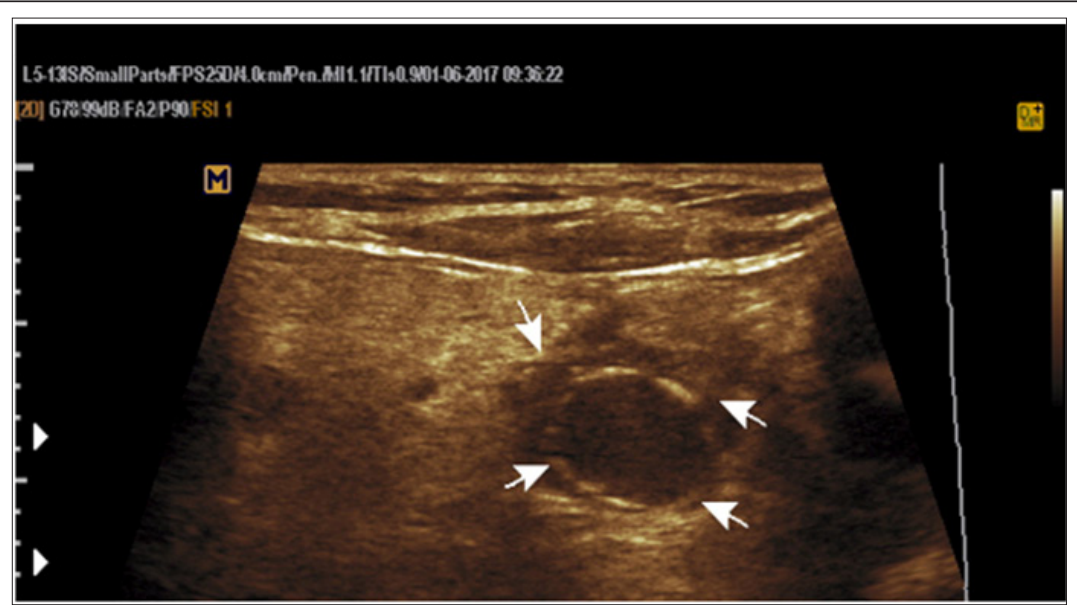

Figure 3: Oval hypoechoic image of the right parathyroid with calcified halo, suggesting ancient enlargement of the gland. 
Hematologic exams showed serum total calcium levels of $9.8 \mathrm{mg}$ / Dl (VR: 8.4 - $10.2 \mathrm{mg} / \mathrm{dL}$ ); plasma phosphorus concentration of $4.9 \mathrm{mg} / \mathrm{dL}$ (VR: 2.3 - $4.7 \mathrm{mg} / \mathrm{D} 00)$; alkaline phosphatase with values of $788 \mathrm{U} / \mathrm{L}$ (VR: 40-150 U/L); and PTH levels higher than $3000 \mathrm{pg} / \mathrm{mL}$ (VR: 15 - 68 pg mL).Incisional biopsy of the lesion showed a fragment of abundantly cellularized dense connective tissue, whose cells exhibit oval/fusiform nuclear morphology and indefinite cytoplasmic boundaries. Histological sections had numerous multinucleated giant cells and hemorrhagic areas. In some regions, there were numerous trabeculae of immature bone tissue and osteoid material, among which were some giant cells(Figure 4). The patient was referred to an endocrinologist for appropriate treatment and follow-up. After two months of biopsy, the patient died to due to multiple organ failure.

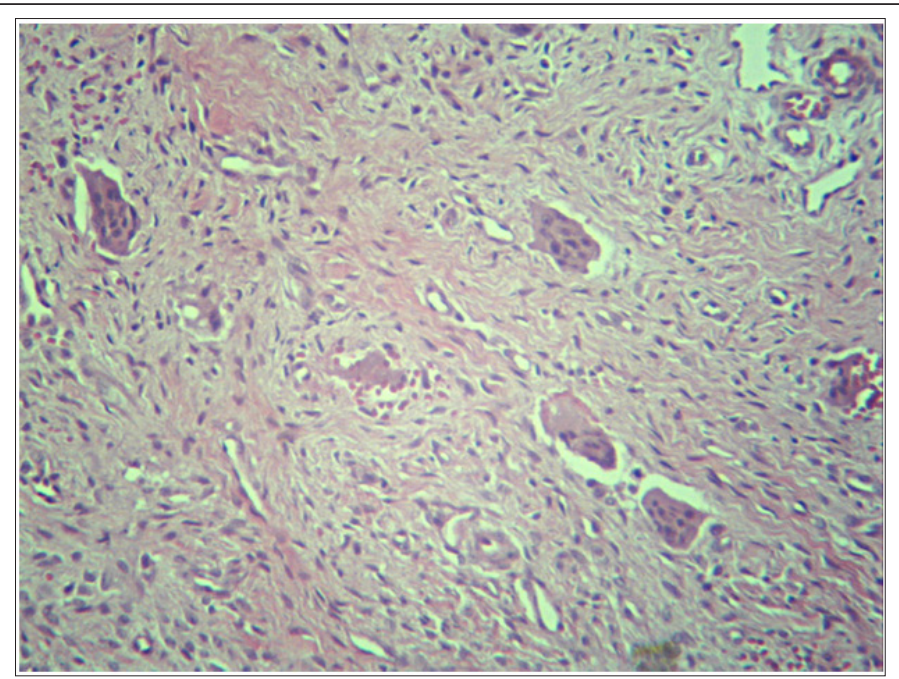

Figure 4: Histopathological analysis of the lesion revealing several multinucleated giant cells dispersed in dense connective tissue with numerous blood capillaries and areas of hemorrhage. Staining with hematoxylin and eosin (HE) - (100x magnification).

\section{Discussion}

Brown tumor is about three times more common in women than in men, and it is more prevalent between over 50-year-old people $[5,6,10]$, as stated in the literature. This tumor can occur in any bone [8], but it is rare in cranial and facial bones, being more frequent in large bones $[1,9,10]$. However, compared to its incidence in maxillary bones, mandible is more commonly affected than the maxilla [5,6].Brown tumor is associated with either primary or secondary hyperparathyroidism, being considered the final stage of the bone remodeling process [10]. In chronic renal patients, its incidence is due to hypocalcemia, hyperphosphatemia and calcitriol deficiency, all characteristic of the disease and which are responsible for the increase in PTH secretion [1], causing morphological alterations in parathyroid glands [6].Calcium and phosphorus concentrations were within or near the normal limits and were explained by hemodialysis. However, the patient's PTH levels were approximately 44 times higher than the normal, with ultrasound examination of the parathyroid showing an increased volume of the gland. Moreover, the alkaline phosphatase levels were approximately five times higher than the normal. Therefore, the diagnosis of secondaryhyperparathyroidism (SHPT) was established.The high levels of PTH are perceived through the presence of osteoblasts and have repercussions on the activation of osteoclasts, providing osteoclastic reabsorption without apposition.

The loss of bone predisposes to microfractures and secondary hemorrhages, which are responsible for the influx of macrophages and growth of repairing fibrous tissue, creating a mass of tissue called brown tumor [11].Thus, the microscopic analysis of the lesion is divided into two main cellular components: mononuclear stromal cells and multinucleated giant cells. A pattern is also observed in cherubism, aneurysmal bone cyst and the most common lesion: central giant cell lesion [12]. Therefore, the differential diagnosis should be judiciously performed as they require differentiated therapy despite having a similar histological pattern.The high levels of endogenous PTH are the reason for the presence and activation of these multinucleated giant cells in the $\mathrm{BT}$, which are believed to be true osteoclasts, justifying the osteolytic properties of the lesions [12].The presence of congestive vessels, areas of hemorrhages and hemosiderin deposits justifies the macroscopic staining of the lesion [1,3].It is important to note that kidney is the major organ involved in the production of bioactive forms of vitamin D (25-OH Vitamin D3) from inert precursors. Consequently, chronic kidney disease is an important risk factor for the development of vitamin D14 deficiency, which, when resulting in hypocalcemia, stimulates compensatory PTH secretion [12].Therefore, since SHPT is strongly related to chronic renal insufficiency, which leads to hypoproduction of vitamin $\mathrm{D}$ and consequent decrease in the absorption of calcium in the intestine [12], it is noted that the increase of PTH secretion plus the installed CKD (which alone already promotes renal osteodystrophy) causes an intense process of generalized osteodystrophy.

Such a process can be seen on CT, showing diffuse hypodense masses in the mandibular bone, even in areas away from the BT, with medullary regions of soft tissue-like density.In general, tumors are asymptomatic except when they are large. Brown tumors can cause facial deformation and compromise the individual's usual functions such as breathing, speaking, and chewing. It may also 
cause headache, visual impairment, dental displacement and mobility, and nasal or oral bleeding [9].When it occurs in the mandible, the main characteristics the patient can present are asymptomatic macrognathia (localized or diffuse), abnormal occlusion, dental mobility, alterations in enamel and dental pulp [2]. In case of a significant deformity in the affected bone, there may be pain and the tumor is easily palpated, having a hard consistency [13].The BT is a late manifestation that occurs in the final stages of SHPT, and therefore PHPT test is rarely indicated prior to situations of decompensation in hemodialysis patients. As for the treatment, it is initially crucial to regularize the PTH levels in order to correct the SHPT by using medications, dialysis, parathyroidectomy or renal transplantation [9].In most cases, the medications for correction of hyperparathyroidism lead to significant regression or complete disappearance of the tumor, although too slowly [2]. The surgical excision is an alternative with immediate results, but which can cause loss of fragments of bones and teeth, peripheral nerve lesions and other aesthetic and functional changes. However, when the tumor is significant and symptomatic, its progression occurs even after the treatment of hyperparathyroidism has started. In addition, the surgical excision should be considered because of the risk of pathological fracture and essential functional impairment $[14,15]$. So, early diagnosis in addiction with multidisciplinary follow-up are important in the control of BT growth and to prevent bone repercussion, like fractures, deformities or even functional alterations[5].

\section{References}

1. Gorsane I, Zammouri A, Meddeb JE, Younsi F, Bartkiz A, et al. (2016) Les tumours brunes chez les hémodialyse's chroniques. Néphrol ther 12(2): 86-93.

2. Pechalova PF, Poriazova EG (2013) Brown Tumor at the Jaw in Patients with Secondary Hyperparathyroidism due to Chronic Renal Failure. Acta Medica 56(2): 83-86.

3. Kalapala L, Keerthi sai S, Babburi S, Venigalla A, Pinisetti S, et al. (2016) An Endocrine Jaw Lesion: Dentist Perspective in Diagnosis - Case Reports in Dentistry.

\section{ISSN: 2574-1241}

DOI: 10.26717/BJSTR.2018.06.001351

Antonione Santos Bezerra Pinto. Biomed J Sci \& Tech Res

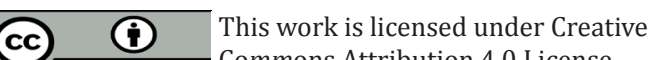

Submission Link: https://biomedres.us/submit-manuscript.php
4. Jeren-Strujic B, Rozman B, Lambasa S, Jeren T, Markovic M, et al. (2001) Secondary hyperparathyroidism and brown tumor in dialyzed patients. Ren Fail 23(2): 279-286.

5. Queiroz IV, Queiroz SP, Medeiros R Jr, Ribeiro RB, Crusoé-Rebello IM, et al. (2016) Brown tumor of secondary hyperparathyroidism: surgical approach and clinical outcome. Oral Maxillofac Surg 20(4): 435-439.

6. Pinto MC, Sass SMG, Sampaio CPP, Campos DS (2010) Brown tumor in a patient with hyperparathyroidism secondary to chronic renal failure. Braz J Otorhinolaryngol 76(3): 404.

7. Porto RA, Truite MR, Bucharles SEG, Hauser AB (2016) Secondary hyperparathyroidism: a Chronic Kidney Disease complication. Rev bras anal Clin 48(3).

8. Santana PHG, Fagundes LS, Silva GBL, Pereira CM (2017) Tumor marrom em maxila associado ao hiperparatireoidismo secundário: relato de caso clínico. J Health Sci Inst 35(1): 55-58.

9. Can Ö, Boynueğri B, Gökçe AM, Özdemir E, Ferhatoğlu F, et al. (2016) Brown Tumors: A Case Report and Review of the Literature. Case Rep Nephrol Dial 6(1): 46-52.

10. Mascarenhas LS, Marchionni AMT, Rebouças DS, Neri JSV, Medrado ARAP (2016) Brown tumor as a result of secondary hyperparathyroidism in chronic renal disease. J Oral Diag : 01.

11. Kumar V, Robbins Sl. Robbins (2010) Patologia Estrutural e Funcional $\left(8^{\text {th }}\right.$ Edn). Rio de Janeiro: Guanabara Koogan.

12. Martins R, Ribeiro Jr O, Curi DS, Borba AM, Alves CAF, et al. (2010) Bilateral brown tumor of primary hyperparathyroidism in the mandible: case report. Rev Clín Pesq Odontol 6(2): 185-190.

13. Jafari-Pozve N, Ataie-Khorasgani M, Jafari-Pozve S, Ataie-Khorasgani M (2014) Maxillofacial brown tumors in secondary hyperparathyroidism: A case report and literature review. J Res Med Sci 19(11): 1099-1102.

14. Filho AJI, Melamed ML (2013) Vitamina D e doença renal. O que nós sabemos e o que nós não sabemos. J Bras Nefrol 35(4): 323-331.

15. Cardoso FNC, Yanaguizawa M, Taberner GS, Kubota ES, Fernandes ARC, et al. (2007) Radiology Contribution for the Evaluation of Secondary Hyperparathryroidism. Rev Bras Reumatol 47(3): 207-211.

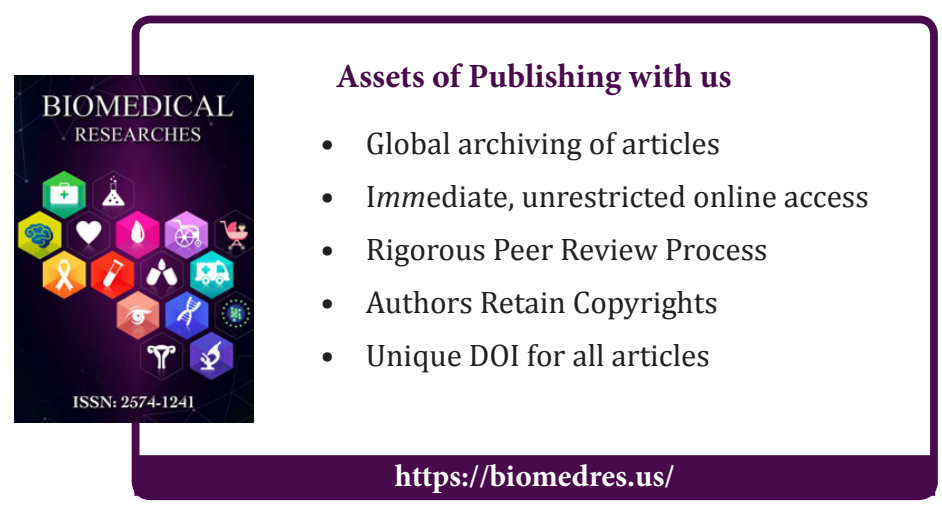

